\title{
Patients' Awareness about the Complications of Diabetes Mellitus and its Co relation with the Glycemic Status
}

\author{
Krishna Kumar Agrawaal ${ }^{1}$ \\ 'Department of Internal Medicine, Universal College of Medical Sciences, Nepal.
}

\section{ABSTRACT}

Introduction: Diabetes is a major cause of morbidity and cardiovascular related mortality along with a major cause of preventable blindness and foot amputation. There are limited studies on diabetes awareness, attitude, and prevalence.

Methods: Thus, we designed a study to seek the patients awareness about the complications associated with diabetes. It was a prospective observational study which included 123 patients with Diabetes Mellitus.

Results: The mean age of population studied was 53 years mainly from the Rupandehi and Nawalparasi districts in Nepal attending a clinic. In the study Erectile Dysfunction was statistically significant with postprandial hyperglycemia. Lack of Awareness about a calorie specific diet plan was significantly associated with increased blood sugar fasting level $>110 \mathrm{mg} / \mathrm{dl}$. A majority of patients (58\%) had awareness regarding kidney damage and $51 \%$ had awareness that Diabetes causes delayed wound healing. Only 3\% of the patients did a regular foot care and $9 \%$ knew what the target glycemic status is. About $36 \%$ know that there can be cardiac complications due to diabetes and $27 \%$ regarding eyes. Similarly $36 \%$ of the patients also knew that there is neuropathy due to diabetes and $18 \%$ were aware about CVA. About $54 \%$ of the patients had Fasting $>110 \mathrm{mg} \%$.

Conclusion: The study showed that though the patients are on OADs but they lack awareness about the major complications related to diabetes mellitus.

Keywords: awareness of diabetic complications; HbA1c; patient awareness.

\section{INTRODUCTION}

Diabetes is an emerging pandemic in the South Asia. As per the International Diabetes Federation, the latest estimates indicate that there are 382 million people living with diabetes. One in twelve has diabetes in South East Asia. ${ }^{1}$

In a study by Nepal Diabetes Association the prevalence of diabetes in population of 20 years and above was estimated to be $14.6 \%$ and $2.5 \%$ in urban and rural areas respectively. ${ }^{2}$ The risk of developing diabetes increases by five times in patients with metabolic syndrome. ${ }^{3}$
As the risk for diabetes is increasing so will be the complications related to this and the trend towards patient's education and self care has to increase. ${ }^{4}$ There are limited studies on diabetes awareness, attitude, and prevalence. ${ }^{5}$ Interestingly patients do a regular blood sugar fasting and postprandial in our setup. So we designed a study to look for the patients awareness about the complications related to diabetes and compare that with the desired blood sugar levels.

Correspondence: Dr. Krishna Kumar Agrawaal, Department of Internal Medicine, Universal College of Medical Sciences, Nepal. Email: agrawalkris@gmail.com, Phone: +977. 9857045721. 


\section{METHODS}

Study Design: Prospective Observational study Duration: 15th November 2014 till 15th March 2015 were enrolled for the study. Consent: Consent from the patients was taken before enrollment. Ethical approval: The study was approved from the Christian Medical College. Inclusion Criteria: Patients with diagnosed Type 2 Mellitus on Medications/MNT with age of diagnosis more than one year. Exclusion criteria: Refusal to give the consent

\section{STATISTICAL ANALYSIS}

A total of 123 patients were enrolled in the study. The data was collected using a structured questionnaire incorporating demographics; assessment of complication awareness. Diabetic control was assessed by the most recent $\mathrm{HbA} 1 \mathrm{c}$ level and last Blood sugar level both fasting and postprandial.

Data were entered in Microsoft excel 2000 and converted into SPSS version 20 for statistical analysis. Percentage, graphical presentation and other descriptive statistics were calculated. The significance level of the data which were taken for the analysis was $\leq 0.05$.

\section{RESULTS}

There were altogether 123 patients who were enrolled in the study. The results are depicted in the following self explanatory tables and graphs.

\begin{tabular}{|c|c|c|c|c|}
\hline Characteristics & Minimum & Maximum & Mean & $\begin{array}{c}\text { Std. } \\
\text { Deviation }\end{array}$ \\
\hline Age in years & 25.00 & 76.00 & 53.50 & 10.76 \\
\hline $\begin{array}{c}\text { Duration of } \\
\text { Diabetes in } \\
\text { years }\end{array}$ & 1.00 & 15.00 & 6.03 & 3.34 \\
\hline Weight in $\mathrm{kg}$ & 42.00 & 86.00 & 58.36 & 9.70 \\
\hline Height in $\mathrm{cms}$ & 139.00 & 176.00 & 155.97 & 7.33 \\
\hline $\mathrm{BMI}\left(\mathrm{kg} / \mathrm{m}^{2}\right.$ & 16.80 & 33.33 & 23.95 & 3.29 \\
\hline $\begin{array}{c}\text { Waist } \\
\text { circumference } \\
\text { in cms } \\
\text { Hip }\end{array}$ & 70.00 & 112.00 & 93.90 & 7.68 \\
\hline $\begin{array}{l}\text { Circumference } \\
\text { in } \mathrm{cms}\end{array}$ & 64.00 & 111.00 & 94.31 & 6.66 \\
\hline Waist Hip ratio & 0.88 & 1.11 & 1.00 & 0.05 \\
\hline $\mathrm{HbA} 1 \mathrm{c}$ in $\%$ & 5.0 & 12.4 & 7.80 & 1.49 \\
\hline
\end{tabular}

\begin{tabular}{|c|c|c|c|}
\hline \multicolumn{4}{|c|}{$\begin{array}{l}\text { Table 2. Showing the different } \\
\text { characteristics at HbA1c }<7 \% \text {. }\end{array}$} \\
\hline $\begin{array}{l}\text { Complications } \\
\text { Awareness }\end{array}$ & Yes & No & $P$ value \\
\hline Eyes & $11(34.4 \%)$ & $24(27.9 \%)$ & 0.494 \\
\hline Kidneys & $17(24.3 \%)$ & $18(37.5 \%)$ & 0.123 \\
\hline Neuropathy & $8(19.0 \%)$ & $27(35.5 \%)$ & 0.061 \\
\hline $\begin{array}{l}\text { Poor Wound } \\
\text { Healing }\end{array}$ & $18(29.5 \% 0$ & $17(29.8 \%)$ & 0.970 \\
\hline IHD & $10(23.3 \%)$ & $25(33.3 \%)$ & 0.249 \\
\hline CVA & $4(20.0 \%)$ & $31(31.6 \%)$ & 0.299 \\
\hline $\begin{array}{l}\text { Awareness } \\
\text { about } \\
\text { Hypoglycemia }\end{array}$ & $5(20.8 \%)$ & $30(31.9 \%)$ & 0.289 \\
\hline $\begin{array}{l}\text { Knowledge of } \\
\text { the Glycemic } \\
\text { status as } \\
\text { recommended }\end{array}$ & $1(11.1 \%)$ & $34(31.2 \%)$ & 0.205 \\
\hline Foot Care & $2166.7 \%$ & $33(28.7 \%)$ & 0.435 \\
\hline $\begin{array}{l}\text { On a diet } \\
\text { based on } \\
\text { calories }\end{array}$ & $1(14.3 \%)$ & $34(30.6 \%)$ & 0.623 \\
\hline $\begin{array}{l}\text { Erectile } \\
\text { Dysfunction }\end{array}$ & $2(14.3 \%)$ & $33(31.7 \%)$ & 0.180 \\
\hline
\end{tabular}

Table 3. Showing the different awareness characteristics at the level of awareness at $\mathrm{HbA1c}$ $>7 \%$.

\begin{tabular}{|cccc|}
$\begin{array}{c}\text { Complications } \\
\text { Awareness }\end{array}$ & Yes & No & P value \\
Eyes & $21(65.6)$ & $62(72.1 \%)$ & 0.494 \\
Kidneys & $53(75.7 \%)$ & $30(62.5 \%)$ & 0.123 \\
Neuropathy & $34(81.0 \%)$ & $49(64.5 \%)$ & 0.061 \\
$\begin{array}{c}\text { Poor Wound } \\
\text { Healing }\end{array}$ & $43(70.5 \%$ & $40(70.2 \%)$ & 0.970 \\
IHD & $33(76.7 \%)$ & $50(66.7 \%)$ & 0.249 \\
CVA & $16(80.0)$ & $67(68.4)$ & 0.299 \\
ED & $12(85.7)$ & $71(68.3)$ & 0.180 \\
Diet & $6(85.7 \%)$ & $77(69.4 \%)$ & 0.627 \\
Glycemic & $8(88.9 \%)$ & $75(68.8 \%)$ & 0.205 \\
status & $1(33.3 \%)$ & $82(71.3 \%)$ & 0.435 \\
Foot care & $19(79.2)$ & $64(68.1 \%)$ & 0.289 \\
Hypoglycemia & 1 & & \\
\hline
\end{tabular}


Agrawaal Patients' Awareness about the Complications of Diabetes Mellitus and its Co relation with the Glycemic Status
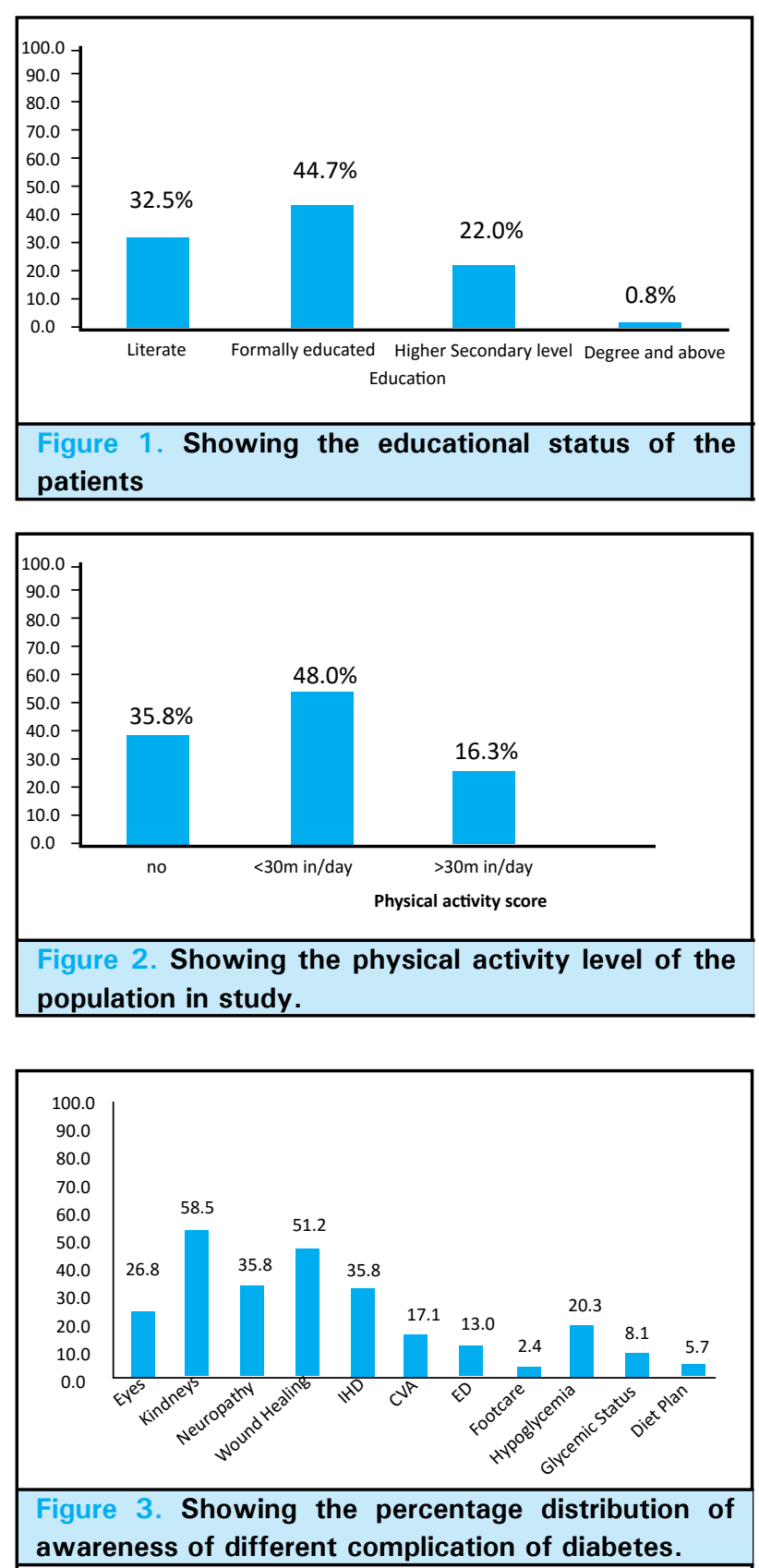

\section{DISCUSSION}

The awareness about diabetes and related issues is poor in general population. ${ }^{6}$ Whereas in diabetic population the awareness about the diabetic complications was observed to be $50 \%$ in a study done in Pakistan. ${ }^{7}$ In our study of 123 patients included $56 \%$ male patients and $44 \%$ female patients. In a study done by Maskey et al in Nepal also showed a Male preponderance whereas other studies have shown a female preponderance. ${ }^{8} \mathrm{~A}$ similar study conducted in Bangladesh by haque et al had a female preponderance in the study. ${ }^{9}$ The mean $\mathrm{BMI}$ in our population was $24 \mathrm{~kg} / \mathrm{m}^{2}$ whereas the mean waist to hip ratio was 1 . Similar findings were observed in the study by Mohan V. ${ }^{10}$ In our study it was observed that about one third patients (33\%) had not received any formal education. The educational status of the study population was significantly associated with the knowledge of glycemic status ( $P$ value- 0.007$)$ and awareness about the foot care $(P$ value-0.001). The physical activity was less than the recommended. In a study conducted in Shivkashi district in India it was found that $74 \%$ of the diabetic population had no awareness regarding the long term effects of Diabetes. ${ }^{11}$ In a population based study in Tamilnadu by Mohan $\mathrm{V}$ et al it was found that only $19.0 \%$ (4951/26001) of whole population knew that diabetes could cause complications. In our study the family history of Diabetes was present in $39.8 \%$ whereas in a urban population study in India it was $38.2 \% . .^{12}$

In our study we observed that there was a majority population with awareness of kidney diseases (59\%). Following this the patient were mainly aware that Diabetes causes Poor wound healing (52\%) followed by Neuropathy $(36 \%)$, affects the heart mainly Ischemic Heart disease (36\%), affects the Eyes $(27 \%)$, Causes Cerebrovacular accidents(18\%), causes erectile dysfunction(14\%), Knowledge of glycemic status(8\%), Awareness about a calorie specific diet plan(6\%) and Foot care(2\%). The awareness to cardiovascular effects with diabetes is low in our study as compared to a similar study where it was $52 \%$ compared to $36 \% .^{13}$

In a study done in Ethopia 67.79\%) had knowledge about long-term complications. ${ }^{14}$ In the study we observed that awareness about neuropathy and the $\mathrm{HbA} 1 \mathrm{c}$ level $>7 \%$ is nearly statistically significant ( $P$ value: 0.06$)$.Similarly Lack of knowledge about a calorie specific diet plan is statistically significant with the blood sugar fasting of $>110 \mathrm{mg} \%$. Similarly lack of awareness about erectile dysfunction was associated with increased postprandial blood sugar level $>140 \mathrm{mg} \%$ (P value 0.02 ). In contrary to our study, a study done in Chandigarh showed that almost two third of the patients with T2DM had good knowledge about the disease. ${ }^{15}$

Our study population had no idea about foot care in Diabetes. Ahmad $\mathrm{J}$ in his article pointed out that approximately $10-15 \%$ of diabetic patients developed foot ulcers at some state in their life and $15 \%$ of all load in amputations are performed in patients with diabetes. ${ }^{16}$

In a nationwide study conducted by the Indian Council for Medical Research it was concluded that the Knowledge and awareness about the Diabetes is poor in India in both the Urban and Rural population. ${ }^{17}$ In an article by Misra A et al, they mention that the key areas that need focus are: generation of awareness, screening of high risk groups, maximum coverage of the population with 
essential medicines, and strengthening primary care. ${ }^{18}$

In a similar study it was observed that the two most important sources were friends \& neighbor (51\%) and family $(49 \%)$ respectively, followed by electronic media $(46 \%)$ whereas in our study it was almost by the healthcare provider. ${ }^{19}$ Ying et al in their study also had finding similar to our study and they also concluded that the main strategy is patients education about the complications. ${ }^{20}$ Nearly all the patients were on some form of medications for the treatment of diabetes. In a survey done by Nepal Health Research Council in 2013 it was indicated that most of the respondents in the survey were on OAD agents $(64 \%) .{ }^{21}$

\section{CONCLUSION}

In this Prospective Observational study it was observed that there is a significant lack of awareness about both microvascular and macrovascular complications in the patients with diabetes mellitus. They also lack awareness about the calorie specific diet plan.

\section{REFERENCES}

1. International Diabetes Federation. IDF diabetes Atlas. Sixth Edition update.International Diabetes Federation 2014.

2. Nepal Diabetes Association[Internet].Kathmandu: Nepal diabetes association; 2014.Available from: www.nepaldiabetesassociation/reseach.php

3. Sharma SK, Ghimire G, Radhakrishnan J, Thapa L, Shrestha NR et al.Prevalence of Hypertension, Obesity, Diabetes and Metabolic Syndrome in Nepal. IJH 2011.

4. Agrawaal KK. Diabetes: Emerging Pandemic. JUCMS: 2014; vol.2 (8):pg.01.

5. Singh A, Milton PE, Nanaiah A, Samuel P, Thomas N. Awareness and attitude toward diabetes in the rural population of Arunachal Pradesh, Northeast India. Indian J Endocr Metab: 2012; 16, Suppl S1:836.

6. N. Murugesan et al. Awareness about diabetes and its complications in the general and diabetic population in a city in southern India. Diabetes Research and Clinical Practice: 2007) 433-437.

7. Chaudhary FMD and SMD. Awareness about diabetes risk factors and complications in diabetic patients: A cross-sectional study. NMJ 2010; 2(3):84-88

8. Maskey R, Shakya DR, Sharma SK, Karki P and Lavaju P. Diabetes mellitus related complications in out- patient clinic of tertiary care hospital. Journal of College of Medical Sciences-Nepal, 2011, Vol-7, No-2, 9-16.

9. Hoque AM, Islam S, Khan AM. Knowledge of Diabetic Complications in a diabetic Population. J MEDICINE 2009; 10(2): 90-93.

10. Mohan V, Sandeep R, Shah D and Varghese C. Epidemiology of type 2 diabetes: Indian scenario. Indian J Med Res 125, March 2007, pp 217-230

11. Kasinathan D, Rajagopalan NG, Marimuthu NP, Ramar M et al. Awareness on Type II Diabetes and Its Complication among Sivaganga District Population in Tamilnadu: A Cross Section Survey. J Adv Sci Res, 2013, 4(1): 38-42
12. Mohan D, Raj D, Shanthirani CS, Datta Manjula, Unwin NC, Kapur A et al. Awareness and Knowledge of Diabete in Chennai- The Chennai Urban Rural Epidemilogy study

13. O suvillan EP, Bhargava A, O'Callaghan M, Buckley U, De Faoite T, Moynihan $\mathrm{K}$ et al. Awareness of diabetes complications in an Irish population. Ir J Med Sci. 2009 Dec;178(4):4016

14. Abdella SH and Mohammed AM. Awareness of diabetic patients about their illness and associated complications in Ethopia. Med-Science .2013; 2(2): 512-522.

15. Kaur S, Mandal L, Nair P, Kaur P, Pathak P and Bhansali A. Awareness among patients with T2DM regarding the Disease at a tertiary care referral center. Journal of Postgraduate Medicine, Education and Research, July-September 2014;48(3):117-122.

16. Ahmad J. The diabetic foot. Diabetes Metab Syndr. 2015 Apr 27. pii: S18714021(00030-2).

17. Deepa M , Bhansali A, Anjana RM , Pradeepa R, Joshi SR , Joshi $P$ et al.Knowledge and awareness of diabetes in urban and rural India: The Indian Council of Medical Research India Diabetes Study (Phase I): Indian Council of Medical Research India. Indian J Endocrinol Metab. 2014 May;18(3):379-85.

18. Misra A, Ramchandran A, Jayawardena R, Shrivastava U and Snehalatha C. Diabetes in South Asians. Diabet Med. 2014 Oct;31 (10):1153-62.

19. Mumu JS, Salehz F, Ara F, Haque R and Ali L Awareness regarding risk factors of type 2 diabetes among individuals attending a tertiary-care hospital in Bangladesh: a cross-sectional study. BMC Research Notes 2014, 7:599. pg:1-9.

20. Tang YH, Pang MCS, Yeung SPG, Yeung TFV. Health literacy, complication awareness, and diabetic control in patients with type 2 diabetes mellitus. JAN.2007 Oct 5:1-10.

21. Aryal KK; Neupane S;Meheta S;Vaidya A; Singh S; Paulin F et al. Non Communicable diseases risk factors: STEPS survey Nepal 2013.Kathmandu: Nepal Health Research Council. 